\title{
Relation between the mucosal flora and Paneth cell population of human jejunum and ileum
}

\author{
MARGARET E ELMES, ${ }^{*}$ MR STANTON,${ }^{*}$ CHL HOWELLS,$\dagger$ GH LOWE $\dagger$ \\ From the *Department of Pathology, and $†$ Public Health Laboratory Service, University Hospital of Wales, \\ Cardiff
}

SUMmARY The Paneth cell population in surgically resected human jejunum and ileum was estimated using image analysis of the granule area in patients who had not received antibiotics. The mucosa was cultured aerobically and anaerobically. In the jejunum 22 samples were sterile and five yielded bacteria; in the ileum four were sterile and three were non-sterile. The mean Paneth cell granule area in the sterile jejunum was $122.7 \pm 37.2 \mu \mathrm{m}^{2}$ and in the non-sterile samples $67.2 \pm 36.6 \mu \mathrm{m}^{2}(\mathrm{p}<0.006)$. The corresponding values for the ileum were $137.9 \pm$ 109.8 and $100.5 \pm 9.1$ (NS). Thus an increase in the Paneth cell population may occur in response to changes in the intestinal luminal environment. Failure of this response and resultant Paneth cell deficiency may lead to bacterial overgrowth.

Using the Paneth cell granule area measured by image analysis as an indicator of the Paneth cell population in the human small intestine we have shown a significant increase in Paneth cells in the jejunum of patients requiring surgery who have had previous partial gastrectomy for peptic ulcer.' We suggested that as Paneth cells may be concerned in the maintenance of a normal bacterial flora in the intestinal lumen, ${ }^{2}$ the proliferation may be an attempt to prevent bacterial overgrowth in an abnormal hypochlorhydric state. This may also occur in other conditions of abnormal gut motility. In a study of the bacterial flora of the small intestinal mucosa in patients requiring intestinal resection ${ }^{3}$ we compared the Paneth cell population of the jejunum and ileum as measured by image analysis in patients who had an intestinal mucosa which was sterile on culture with those whose mucosa yielded bacteria.

\section{Material and methods}

Patients requiring surgical resection of the small bowel who had not received preoperative antibiotics were studied; ethical approval for the collection of samples of mucosa was obtained. Twenty seven samples of jejunum and seven samples of ileum were examined. Jejunal samples were obtained from 14 men (mean age 63.6 \pm 11.0 years), and 13 women (mean age $63.6 \pm 12 \cdot 8$ years). The indica-

Accepted for publication 30 July 1984 tions for surgery were: carcinoma of the stomach 12 , other neoplasms of stomach or small bowel 5, peptic ulcer (first operation) 3, complicated peptic ulcer requiring a second operation 5 , pancreatitis 1 , and jejunoileal bypass 1 . The ileal samples came from two males (aged 15 and 23) and five women (mean age 53.6 \pm 20.4 years). The indications for surgery were carcinoma of the caecum 2, Crohn's disease 2, Meckel's diverticulum 2, carcinoma of the small bowel 1.

Mucosa was collected from the operating theatre in sterile plastic bags, and after a sample had been taken for histology using a sterile knife the remainder was put into preweighed bijou bottles containing $5 \mathrm{ml}$ glycerol transport broth and refrigerated before homogenisation and culture. Details of the subsequent procedure are given elsewhere. ${ }^{3}$

The samples for histology were fixed in formolsaline, embedded in wax, cut at $4 \mu \mathrm{m}$, and stained with a modification of Lendrum's phloxine tartrazine as described previously. ${ }^{1}$ The granule area per crypt (in $\mu \mathrm{m}^{2}$ per crypt) was measured in 25 crypts per patient, as described previously; all measurements were made on an IBAS 2 image analyser.

The IBAS 2 television image analyser (Fig. 1) enables monochrome pictures received from a microscope coupled television camera to be stored and enhanced, making it possible for image associated parameters to be accessed and measured. The Paneth cells are observed under a $\times \mathbf{4 0}$ objective. To improve the contrast of the image an interference 


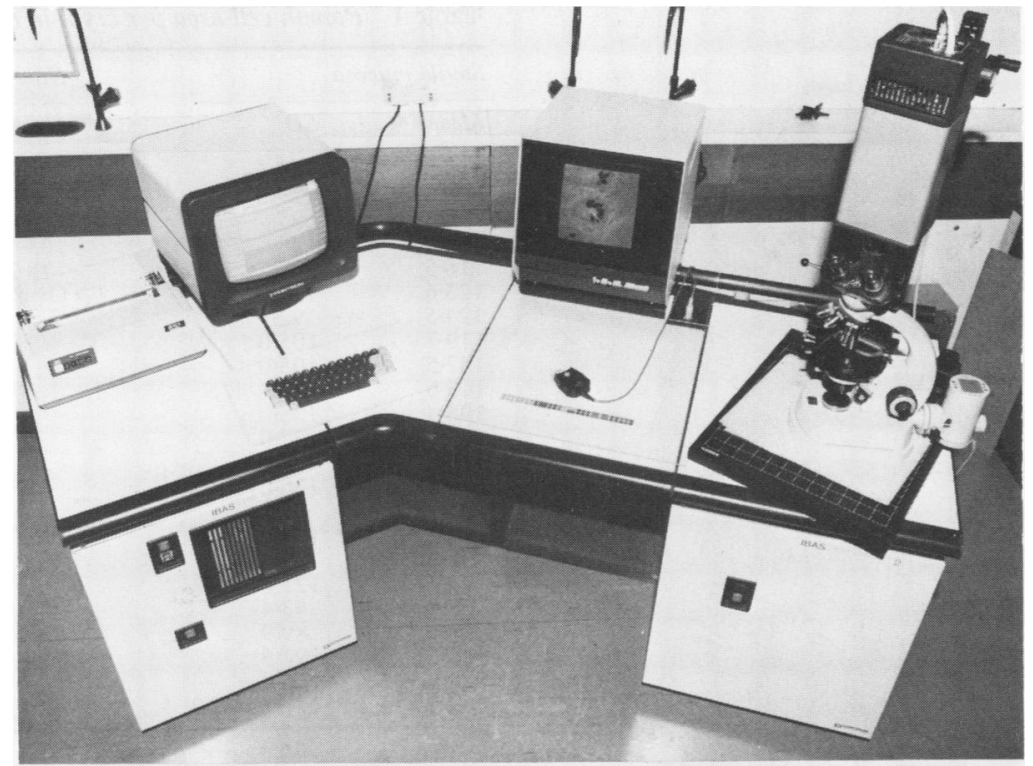

Fig. 1 General view of the IBAS 2 Image Analyser prepared for Paneth cell area measurement. The central monitor shows the Paneth cell image that has been obtained from a slide under the microscope on the right of the picture.

filter is placed in the incident light path of the microscope. This makes the Paneth cells appear black against a lighter mucosal background (Fig. 2a). After the cells have been identified the image is stored in a memory comprising $512 \times 512$ picture elements (pixels). Each element also has a digital "grey" value between 0 (black) and 255 (white). The areas occupied by the cell granules are then separated from the background by adjustment of the threshold control (Fig. 2b). These areas are then transferred from the memory which contains the original image to an adjacent memory, where they are measured.

Regions which share the same range of densities, such as entero-chromaffin cells, are selected as well as the Paneth cell granules and are edited out by means of an operator controlled digitiser tablet. The numerical value of the Paneth granule area is then displayed in units of square microns $\left(\mu \mathrm{m}^{2}\right)$. The image analyser is calibrated using a stage micrometer. An IBAS calibrator function is then used to calculate (and store) the relation between the television system and the micrometer.

All the above procedures are carried out by a computer program. Operator intervention occurs at three stages, which are: $(a)$ selection of the appropriate region from the slide; $(b)$ adjustment of the threshold (discrimination) level; (c) editing of any artefact.

\section{Results}

A Paneth cell granule area measurement was carried out on 35 suitable specimens: 27 jejunum and 8 ileum. In the jejunum a sterile mucosa was found in 22 of 27 samples, and five yielded bacteria on culture. The mean Paneth cell granule area in the sterile jejunum was $122 \cdot 7 \pm 37 \cdot 2 \mu \mathrm{m}^{2}$, and in the non-sterile group the mean value was $67.2 \pm$ $36.6 \mu \mathrm{m}^{2}(\mathrm{p}<0.006)$ (Table 1). The organisms isolated are shown in Table 2.

In the ileum five specimens were sterile and three were non-sterile; the mean Paneth cell areas were $137 \cdot 9 \pm 109 \cdot 8$ and $100 \cdot 5 \pm 91 \cdot 1$, respectively (NS) (Table 3). It can be seen that the patients with sterile mucosae had a higher mean Paneth cell area than those with non-sterile mucosae, although the difference was not statistically significant.

\section{Discussion}

We have previously shown that patients with bacteria in the jejunal mucosa have fewer Paneth cells than those with mucosa which is sterile on culture.

Most of the jejunal samples were sterile on culture. Those with bacteria were from patients with carcinoma of the stomach or duodenum or those who had had a previous partial gastrectomy with consequent hypochlorhydria and flow disruption. The 


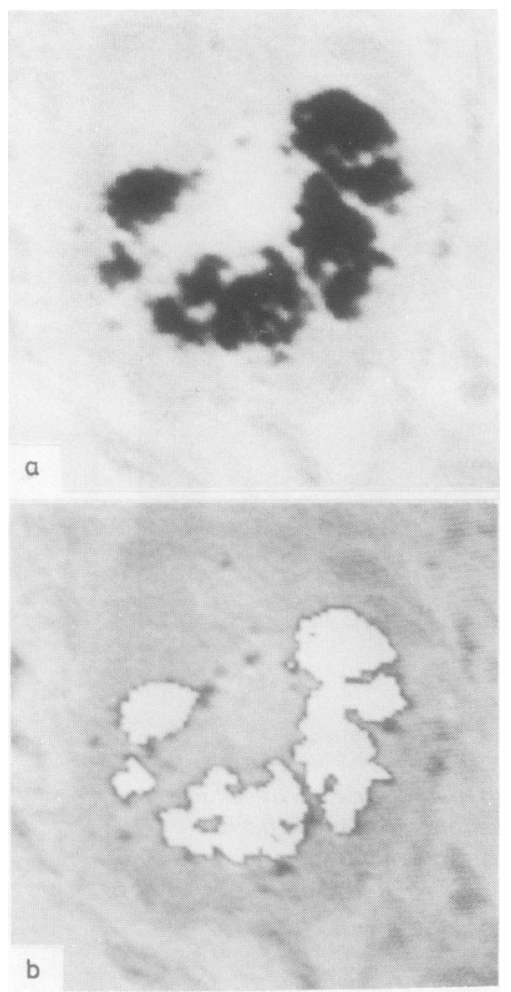

Fig. 2 Paneth cell images as seen on the monitor. (a) Initial image. (b) Image separated from the background using the threshold control.

three patients with peptic ulcer had sterile mucosae. The Paneth cell population was considerably smaller in patients with non-sterile mucosae, which suggests that Paneth cell deficiency is associated with bacterial proliferation.

The number of ileal samples was small as few patients come to intestinal surgery without receiving some antibiotic, usually prophylactically, and even an antibiotic given with premedication was consi-
Table 1 Paneth cell area per crypt in the jejunum $\left(\mu^{2}\right)$

\begin{tabular}{|c|c|c|c|}
\hline \multicolumn{2}{|c|}{ Sterile mucosa } & \multicolumn{2}{|c|}{ Non-sterile mucosa } \\
\hline Mean & $S D$ & Mean & $S D$ \\
\hline $\begin{array}{r}110 \cdot 0 \\
135.3 \\
136.3 \\
96.8 \\
116.5 \\
123.6 \\
124 \cdot 5 \\
119.7 \\
137.5 \\
113.6 \\
198.4 \\
169.7 \\
76.8 \\
140.8 \\
108.5 \\
111.5 \\
96.3 \\
97.4 \\
58 \cdot 8 \\
78.3 \\
122.6 \\
220.0 \\
\text { Overal }\end{array}$ & $\begin{aligned} 86 \cdot 1 \\
127 \cdot 0 \\
87 \cdot 7 \\
126 \cdot 0 \\
87 \cdot 7 \\
110 \cdot 0 \\
92 \cdot 5 \\
105 \cdot 0 \\
105 \cdot 0 \\
75 \cdot 4 \\
125 \cdot 0 \\
137 \cdot 0 \\
63 \cdot 6 \\
130 \cdot 0 \\
92 \cdot 8 \\
107 \cdot 0 \\
69 \cdot 4 \\
125 \cdot 0 \\
53 \cdot 4 \\
89 \cdot 9 \\
97 \cdot 5 \\
166 \cdot 0 \\
122 \cdot 7 \pm 37 \cdot 2\end{aligned}$ & $\begin{array}{c}26.8 \\
50.7 \\
56.0 \\
123.6 \\
78.2 \\
\text { Overal }\end{array}$ & $\begin{array}{c}35 \cdot 7 \\
50 \cdot 1 \\
57 \cdot 3 \\
113 \cdot 0 \\
67 \cdot 2 \\
67 \cdot 2 \pm 36 \cdot 6\end{array}$ \\
\hline
\end{tabular}

Pooled t test: $\mathrm{t}=3.02 \mathrm{p}<0.006$.

dered a contraindication to inclusion in the study. The proportions of sterile and non-sterile mucosa were roughly equal. The two patients with Crohn's disease and one with carcinoma of the caecum were non-sterile, and the remainder were sterile. The mean Paneth cell count in the sterile mucosa cases was higher than in the non-sterile cases, although the difference was not significant.

In our previous study ${ }^{2}$ we found pronounced Paneth cell proliferation in patients who had had a previous partial gastrectomy and postulated that this was a response to an altered $\mathrm{pH}$ and flow which could lead to bacterial overgrowth. The present work confirms that when Paneth cell proliferation does not occur bacteria may be isolated from the mucosa. The mechanism of this response or failure of response requires further investigation.

We thank Dr T Khosla for statistical advice, Dr JP

Table 2 Organisms isolated from patients with non-sterile mucosa

\begin{tabular}{|c|c|c|c|c|c|}
\hline & $\begin{array}{l}\alpha \text {-haemolytic } \\
\text { streptococci }\end{array}$ & $\begin{array}{l}\text { Streptococcus } \\
\text { faecalis }\end{array}$ & Enterobacteriaceae & Anaerobes & Others \\
\hline \multicolumn{6}{|l|}{ Jejunum } \\
\hline Duodenal ulcer (2nd operation) & + & & & & \\
\hline Gastric carcinoma & & & & + & \\
\hline Gastric carcinoma & & & + & & \\
\hline Carcinoma of the duodenum & + & & & & \\
\hline Gastric carcinoma & + & & + & & \\
\hline \multicolumn{6}{|l|}{ Ileum } \\
\hline Carcinoma of the caecum & + & + & + & + & \\
\hline Crohn's disease & & + & + & & \\
\hline Crohn's disease & & & + & & \\
\hline
\end{tabular}


Table 3 Paneth cell area per crypt in the ileum $\left(\mu^{2}\right)$

\begin{tabular}{|c|c|c|c|}
\hline \multicolumn{2}{|c|}{ Sterile mucosa } & \multicolumn{2}{|c|}{ Non-sterile mucosa } \\
\hline Mean & $S D$ & Mean & $S D$ \\
\hline $\begin{array}{c}185 \cdot 1 \\
82.9 \\
166 \cdot 1 \\
117 \cdot 6 \\
\text { Overal }\end{array}$ & $\begin{array}{c}87.9 \\
62.9 \\
136.9 \\
112 \cdot 3 \\
137 \cdot 9 \pm 109 \cdot 8\end{array}$ & $\begin{array}{r}97 \cdot 6 \\
114 \cdot 7 \\
89 \cdot 1 \\
\text { Overa }\end{array}$ & $\begin{array}{c}87 \cdot 9 \\
98 \cdot 6 \\
88 \cdot 1 \\
n 100 \cdot 5 \pm 91 \cdot 1\end{array}$ \\
\hline
\end{tabular}

Pooled $t$ test: $t=0.49$ (NS).

Clarkson for general assistance, and the surgeons of the University Hospital of Wales for their cooperation in obtaining samples of mucosa.

\section{References}

' Elmes ME, Gwyn Jones J, Stanton MR. Changes in the Paneth cell population of human small intestine assessed by image analysis of the secretory granule area. J Clin Pathol 1983;36:867-72.

2 Elmes ME, Gwyn Jones J, Stanton MR, Howells CHL, Lowe GH. Peptic ulcer surgery and the Paneth cell. Scand J Gastroenterol 1982;17:161-2.

${ }^{3}$ Elmes ME, Howells CHL, Lowe GH. Mucosal flora of the small intestine and the effect of preoperative antibiotics. J Clin Pathol 1984;37:1272-5.

Requests for reprints to: Dr Margaret E Elmes, Department of Pathology, University Hospital of Wales, Cardiff, Wales. 